\title{
Application and Functional Requirements of Simulator in Harbor and Waterway Design
}

\author{
Chaojian Shi* \\ * Shanghai Maritime University Merchant Marine College \\ 항만 및 항로 설계에 있어서 시뮬레이터의 응용과 필요성 \\ 施 朝 健 \\ *中國 上海海運學院 商船學院 教授
}

\begin{abstract}
The roles and importance of the application of simulator in harbor and waterway design are emphasized. On this paper Different methods of simulation and their application are described. A large-scale simulation concept, group simulation, is proposed. Requirements of the simulator for accomplishing the tasks properly and effectively are suggested. Some points on modeling of ship hydrodynamics and environmental factors, which are critical especially in waterway design simulation, are discussed and algorisms presented.
\end{abstract}

Key words : Simulation, Waterway, Environmental Factor, Ecdis, Interaction, Bank Effect

요 약 : 항만 및 항로의 설계에 있어서 시물레이터 적용의 중요성과 그 기능이 강조되고 있다. 본 연구에서는 시물레이션의 다른 방법과 그 적용에 대하여 소개하였고, 대축척 시물레이션의 개념, 그룹시물레이션을 제안하였다. 이 과업을 적절하고 효과적으로 수행가기 위하여 시뮬레이터의 요구조건을 제시하였고, 특별히 항로설계 시뮬레션에서 가장 중요한 선박의 동하중 모델링에서의 몇가지 관점과 주위환경 요소를 설명하고 알고리즘을 나타내었다.

핵심용어 : 시뮬레이션, 수로, 환경조건, 전자해도, 상호작용, 측벽영향

\section{Introduction}

Most of the navigation simulators nowadays, especially those in Asia, are designed and installed mainly for education and training purpose. But simulators have long been used as valuable tools in harbor and waterway design. It is predictable that simulators should play even more important role in this area with the development of both computer and marine simulation technologies. It is of significance to make studies on application of simulators in waterway design and maintenance. Considering special functional requirements when designing and installing simulators will improve the performance and outcomes of the simulation.

Simulation assists the design and decision process by allowing alternative harbor and waterway designs to be examined without real risk and without the capital investment

* 정회원. cjshi@shmtu.edu.cn, 008621-58855200 of implementing of a untested design. By allowing the examination of a variety of alternative designs, together with special combinations of ships, electronic aids, environmental conditions and operational practices, simulation can provide a design tailored as a special solution to the conditions in a specific port. The simulation process and the data analyses are of benefit for the design engineer to determine design berthing area and turning basin dimensions, outbound lane width, asymmetric or bended channel dimension, etc. It also helps the operator evaluate the effectiveness of navigation aids, determine the safe operational margins of environmental factors such as maximum wind force or current velocity.

\section{Methods of simulation}

Ship navigation is a complicated process, as Fig. 1 shows. It operates as a system composed of the ship, the shiphandler, the environment and other related parties. No 
simulator installed up to now can simulate all the factors. According to different requirements, different method of simulation to a variable extent can be employed. It should be noted that the more factors to be involved in the simulation, the more valid the result will be and on the other hand, the more time and cost will involve.

\subsection{Fast Time computer Simulation}

Fast-time computer simulation usually employs desktop shiphandling simulators. A desktop simulator can be an ordinary computer with relating software. Some of them may be operated with simplified rudder and engine operating units. A desktop simulator may include the following features,

- Ship hydrodynamic models responding to rudder, thruster and engine operation,

- Environmental effects such as wind, current effect,

- Geographical effects such as water depth and channel bank.

Because of the simplicity of the hardware, multiple equipments can be employed during the simulation. Time of simulation can be accelerated if needed. Therefore the process of simulation is relatively fast and expensive. It can screen large number of alternatives and more data can be achieved for specific interests. This method is effective when performing the following tasks,

- Validation of hydrodynamic ship models,

- Examination of waterway alternatives (different width and depth),

- Examination of environmental conditions (different wind force and current velocity),

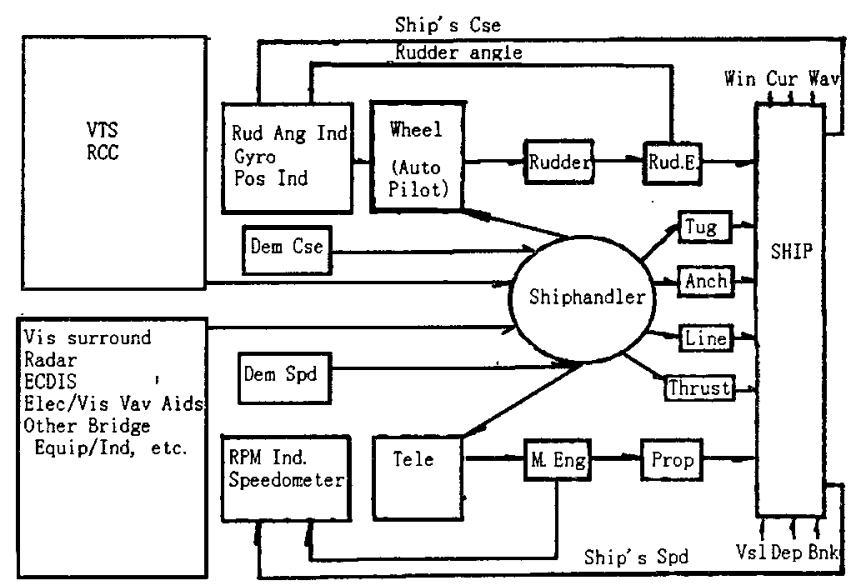

Fig. 1 Ship navigation process as a system
- Examination of operational procedures.

- Preparation for more sophisticated simulations.

\subsection{Real Time Man-In-The-Loop Simulation}

Real-time, man-in-the-loop simulation involves multitask or full-mission shiphandlingsimulators. Compared to the desktop simulators, following features are added,

- A visual system displaying relatively wide scope of waterway image (120-360 degrees horizontally)

- An enclosed space similar to a ship bridge with relevant equipment and indicators (Radar, GPS, speed $\log$, rudder and rpm indicators, etc.)

- Line, Anchor and tug operating consoles.

The conning officer operates the simulated ship by issuing engine, rudder, or tug/thruster commands. The engine and rudder commands are carried out at the ship's console by other team members through equipments similar to that in a real bridge. The hydrodynamic program calculates the resultant vessel movement based on these inputs and environmental conditions. The ship's motion is then shown on the visual and radar displays, as well as other equipments such as ECDIS, GPS, log, etc. If necessary, the conning officer responds to this movement by issuing additional commands. This interaction of the mariner and the simulation process is known as "manin-the-loop"

Real-time, man-in-the-loop simulation is employed when performing,

- Realistic simulation of environment

- Assessment of the effect of human factors,

- Real-time and high fidelity operations, etc.

\subsection{Group simulation}

With the wide spread use of simulator in education and training, the simulator functions are becoming more and more sophisticated and the fidelity and validity greatly improved. Danish Maritime Institute has integrated the bridge and engine-room simulator systems and set up integrated engine and bridge simulation courses for crew training. It is reported that the cooperation between the engine and bridge crews is essential for safe navigation and especially important in crisis situations (Bay [1]). Donaldson Consulting Group in the United States of America designed and conducted a program entitled Joint 
Bridge Team Training for Tankers, tugs, and Pilots. The objective of the training program is to bring together of members of the 'larger team' who perform critical roles in a tankers safe and successful transit and ask them to learn together. The program was aimed at representatives form a tanker company, a tug company, and several harbor pilot organization tie to the ship escort, assist, and passage of tanker in U. S. West Coast waters. The program was conducted on a training facility where the program trainers could employ the use of three ship navigation simulators and have trainees operate the simulated vessels interactively over a series of realistic simulated voyages (Donaldson [2]). The integrated simulator in Shanghai Maritime University can also be set into a working mode in which the four radar simulator stations act as real time man-in-the-loop operated tugs (Shi [6]).

With modern large-scale marine simulators, it is feasible to perform combined simulation of tow or more simulators. Combined simulation provides port navigation process with more fidelity and validity. Therefore the result of the simulation can be used to examine the harbor and channel design more thoroughly.

Shiphandling simulator is still the hart of the simulation but the following features are included,

- Real-time, man-in-the-loop tugs and other ships,

- Man-in-the-loop engine operation with engine room simulator,

- VTS operation (preferably with a VTS simulator).

\section{Simulator Requirements}

In most of the simulation projects for harbor and waterway design, at least two simulation methods, i.e. fast-time and man-in-the-loop methods, should be employed. Those projects should be performed with multi-task or fullmission simulators.

For fast-time simulation, the amount of test to be performed may be very large. Multiple desktop stations can be employed. These stations can be operated either in independent mode or in networked mode. Preferably the display mode can be either $3-\mathrm{D}$ or $2-\mathrm{D}$. Usually $2-\mathrm{D}$ representation such as radar or ECDIS is quite effective with this method.

As for man-in-the-loop simulation, usually a conning officer who is licensed for, or very experienced in, the project area is needed to perform the simulation. He depends on visual cues such as formal aids-to-navigation (light houses and buoys) and informal aids such as steeples, transmission towers, buildings, etc. They also need to know the location of their vessel relative to land, docks, bridges, other vessels, etc. Therefore, the simulator must provide a visual representation of both the simulated vessel and the project area. Although in real life, most mariners seldom use radar unless they are operating in limited visibility. During simulation runs however, the radar provides an important supplement to the visual scene because distances are much easier to determine in the plan view. Another important equipment is ECDIS. Not all simulators are incorporated with ECDIS equipment now. But the situation will change because more and more ships are equipped with ECDIS and ECDIS simulator is becoming a necessary training tool. The Marine Safety Committee, at its seventy-fourth session (30 may to 8 June 2001) approved the Interim Guidance on Training and Assessment in the Operational Use of the Electronic Chart Display and Information System (ECDIS) Simulators (IMO [3]). This will speed up the installation of ECDIS simulators. Compared with radar display, ECDIS offers more direct information about the ship movements in waterways. Use of ECDIS display in waterway simulation will be of great help to the design.

For group simulation we need an engine room simulator and several tug stations networked to the shiphandling simulator. Usually we don't have as many VTS simulators as shiphandling ones. Roles of VTS operation can be performed by a properly manned communication station.

In almost all the cases in harbor and waterway design, waterway data must be collected and modeled. Therefore a database modeling system must be incorporated with the simulator. The system shall provide a database input facility to allow the user to create a new port or waterway area as well as add or modify an existing database.

For harbor and waterway design simulation, offline data processing system is important and must also be incorporated.

\section{Ship Mathematical Model}

The heart of the marine simulator is the hydrodynamic model used to calculate ship response to the variety of forces being exerted upon the vessel. Forces causing ship motion are both environmental and mariner controlled. Environmental forces are caused by wind, current, bank 
effects, shallow water, ship interaction, and waves. Mariner controlled forces are the results of rudder angle, propeller revolution, tugs, and bow and stern thrusters, lines and anchors. These forces cause six degrees of ship motion: three degrees of horizontal motion (surge, sway, and yaw) and three degrees of vertical motion (heave, pitch, and roll).

Wave action is the primary force causing vertical ship movement. Because of the confined water space and relatively shallow water in port areas, waves usually have less effect on the simulation. Therefore, many navigation channel design simulations have been successfully conducted using only the three degrees of horizontal motion. One of the effective mathematical models for shiphandling simulators is described by Equation (1)-(3).

$$
\begin{aligned}
& m\left(\dot{u}-v r-X_{G} r^{2}\right)=X \\
& m\left(\dot{v}+u r+X_{G} r^{2}\right)=Y \\
& I_{z} \dot{r}+m X_{G}(\dot{v}+u r)=N
\end{aligned}
$$

Where $m=$ mass of the vessel

$$
\begin{aligned}
& I_{Z}=\text { moment of inertia about } z \text {-axis } \\
& u=\text { velocity of forward or astern motion } \\
& v=\text { velocity of sideways motion } \\
& r=\text { turning rate of the ship's heading } \\
& X=\text { summation of forces along the longitudinal axis } \\
& Y=\text { summation of forces along the lateral axis } \\
& N=\text { summation of moments about the vertical axis } \\
& X_{G}=\text { position of gravity center on } \mathrm{x} \text {-axis }
\end{aligned}
$$

This type of model is based on the forces acting on the ship. It is convenient to include all contributing factors to the ship movement as long as it can be represented in terms of forces. In order to calculate the forces variety of coefficients must be determined. This may involve complicated captive model and full-scale tests as well as theoretical deductions.

Equation (4) and (5) offer another type of mathematical model.

$$
\begin{aligned}
& \dot{V}+a_{v v} V^{2}+a_{\delta \delta} \delta^{2} V^{2}+a_{n} \gamma^{2}=a_{n n} n^{2}+a_{n v} n V \\
& T_{1} T_{2} \ddot{\gamma}+\left(T_{1}+T_{2}\right) \dot{\gamma}+\gamma+\alpha \gamma^{3}=K \delta+K T_{3} \delta \\
& \text { where } \mathrm{V}=\text { speed of the vessel } \\
& \begin{array}{c}
\gamma=\text { rate of turn } \\
n=\text { engine rpm } \\
\delta=\text { rudder angle }
\end{array}
\end{aligned}
$$

\subsection{Varying Current Acting on Ship's Hull}

Current has strong effect because of high density of

\author{
$T_{1}, T_{2}, T_{3}=$ time constants \\ $a_{\mathfrak{v} v}, a_{s \delta}, a_{\gamma \gamma}, a_{n n}, a_{n v}, \alpha=$ hydrodynamic coefficients
}

This model sometime is referred to as response model because it is based on the general response of the ship to the maneuvering operations such as rudder angle and engine rpm. This model will be very useful when trying to model a ship with the sea trial or maneuvering test results.

In harbor and waterway design simulation, a question involved is selecting of ship model to be used. The most convenient way will be picking up the models already in the model library of the simulator. If the ship model library is properly built or supplied by the manufacturer, this will work well in many cases. When the harbor or waterway is for some design ships which are not available in the library of simulator involved, new models should be developed. If the design ship is some typical existing ship type, the model can be developed based on the ship data, trials and tests. Sometimes the harbor or waterway is designed for future ships, e.g. Yangshan deepwater harbor of Shanghai for $6^{\text {th }}$ generation container ships. Predicted characteristics based on the ship particulars should be employed. This may involve plenty of work such as model tests and theoretical calculations. It is recommended here making an 'open model' for IMO standard ship. 'Open model' is a ship mathematical model module which can be redefined by the user. IMO standard ship means the ship's maneuvering characteristics are on the margin specified by IMO (IMO [4]), as shown in Fig. 2 to Fig.5. Because the real ship behaves better than IMO standard ship of relevant size, simulating with IMO standard ship will make a check of safety margins for ship navigation of the harbor and waterway concerned.

\section{Environmental factor Consicieration}

In harbor and waterway design simulation, environmental conditions are key factors to be taken into account. In most cases harbor and waterway design simulation is performed in water space with limited width and depth. The ship interaction and bank effect become more prominent. The geographical feature makes the current more complicated. 


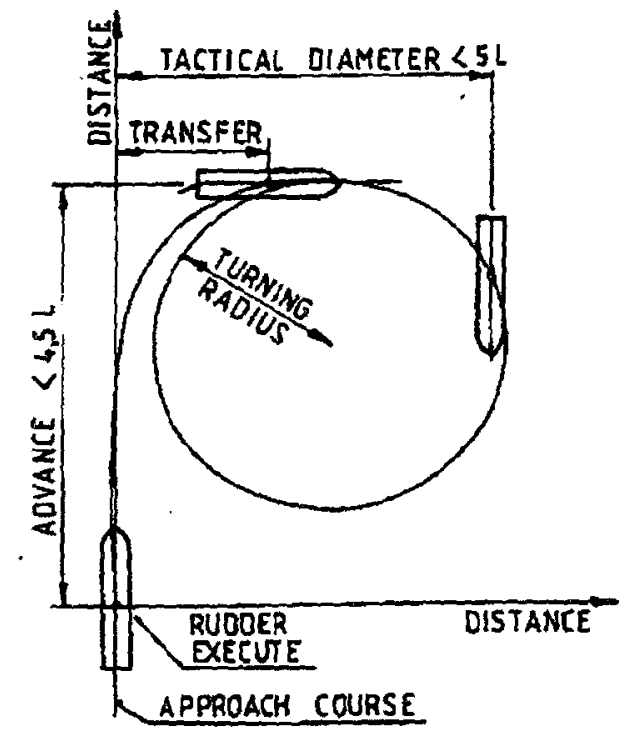

Fig. 2 Turning Circle

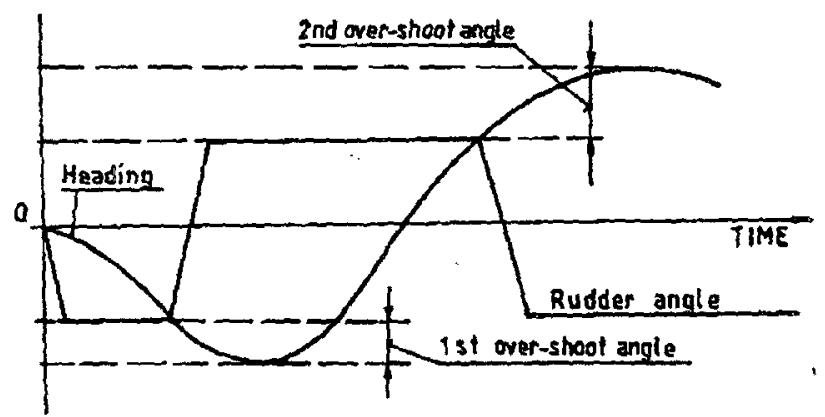

In $10 / 10^{\circ}$ zig-zag test: first overshoot angle should not exceed $10^{\circ}$, if $L / V<10 \mathrm{~s} 20^{\circ}$ if $L / V>30 \mathrm{~s}$. Second overshoot angle should not exceed the above by more than $15^{\circ}$.

Fig. 3 Yaw Checking Ability

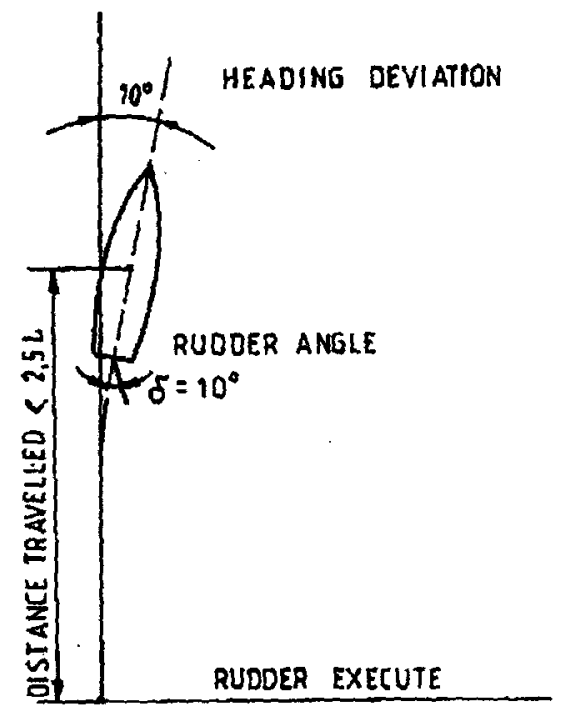

Fig. 4 Initial Turning

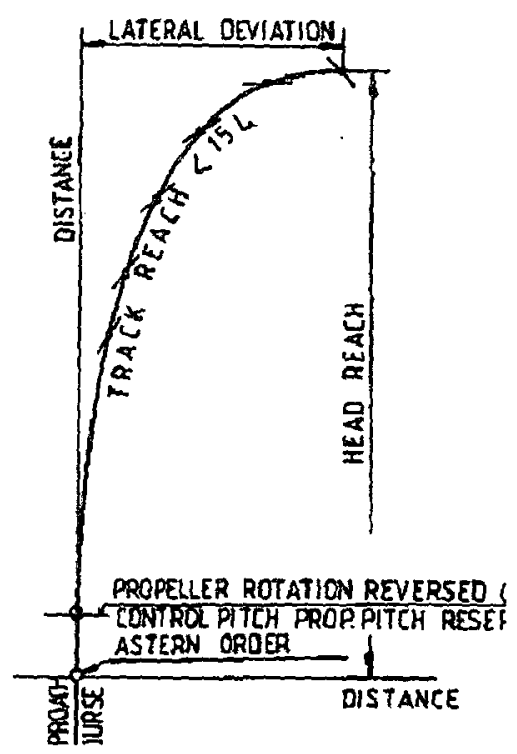

Fig. 5 Crash Stopping

water. It acts on the under water portion of the ship. In most cases it can be assumed that the current velocity and direction are the same along the ship's hull. Therefore equation (6)-(8) can be employed to describe the current forces and moment acting on the ship.

$$
\begin{aligned}
& X_{c}=\frac{1}{2} \rho A_{F W} V_{c}^{2} C_{x}(\beta) \\
& Y_{c}=\frac{1}{2} \rho A_{S W} V_{c}^{2} C_{y}(\beta) \\
& N_{c}=Y_{c} L_{p c}
\end{aligned}
$$

Where $X_{c}, Y_{c}=$ longitudinal and lateral forces caused by current.

$A_{F W}, A_{S W}=$ lateral and longitudinal areas of under water portion.

$\beta=$ attack angle of the current to the hull

$C_{x}(\beta), C_{x}(\beta)=$ longitudinal and lateral coefficients of current force.

$\rho=$ Water density

$V_{c}=$ Current velocity

$N_{c}=$ turning moment

$L_{p c}=$ lever of the force caused by current

In channel design navigation simulation the effect of current is critical and should be represented as precisely as possible. In some parts of the port area current acting on the hull may vary longitudinally, e. g. passing a bend (Fig. 6) or entering berth area (Fig. 7), etc. Usually those parts of the area are also the key portions of the channel that 


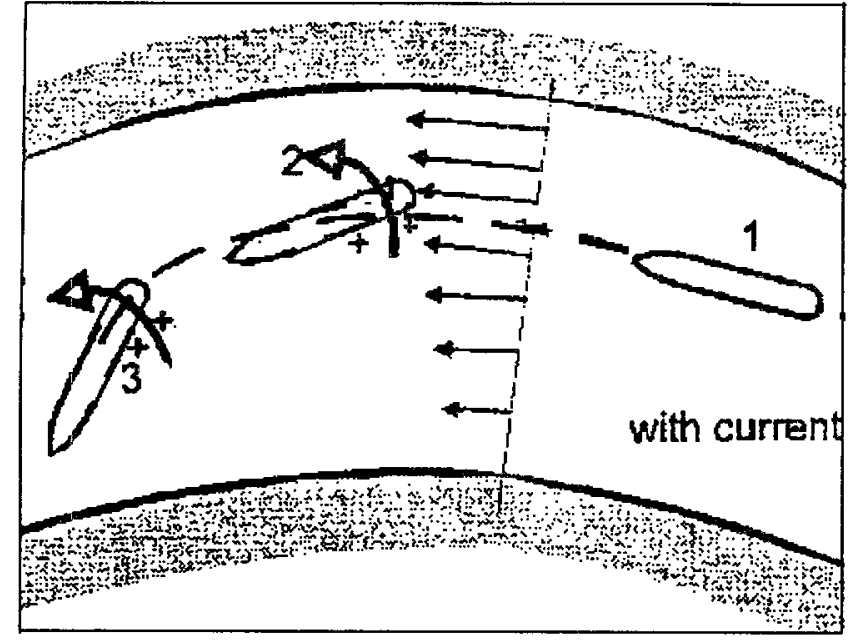

Fig. 6 Passing Bend

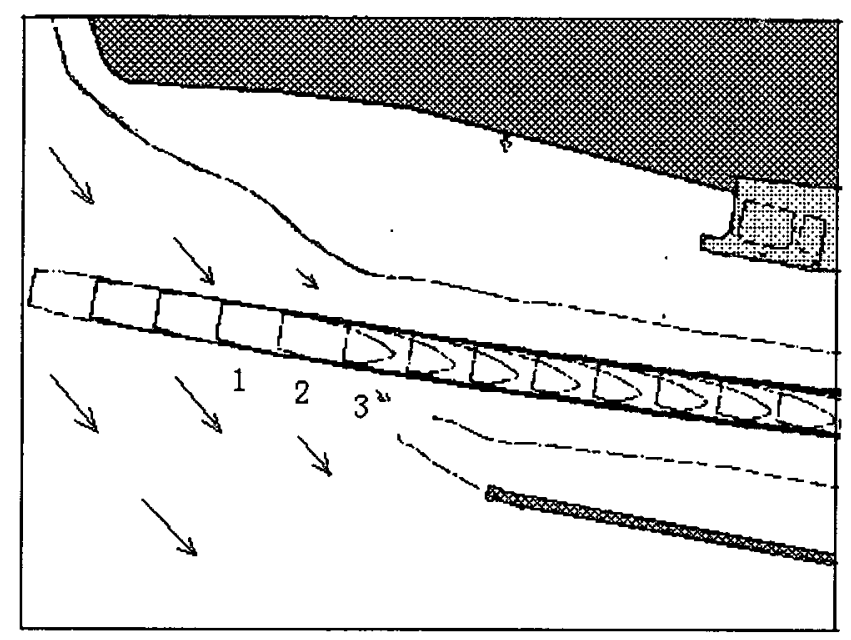

Fig. 7 Entering Berth Area

need to be examined with special care in the simulation. An effective way to calculate the effect of varying current is by dividing longitudinal underwater portion of the ship into several sections. Lateral force for each section is calculated using equation (9).

$$
Y_{c i}=\frac{1}{2} \rho A_{c i} V_{c i}^{2}
$$

Where $Y_{c i}=$ lateral forces on $i$-th section

$$
\begin{aligned}
& A_{c i}=\text { Area of } \mathrm{i} \text {-th section } \\
& V_{c i}=\text { Average current velocity of } \mathrm{i} \text {-th section }
\end{aligned}
$$

And the overall lateral force and turning moment can be attained by equation (10) and (11).

$$
Y_{c}=\sum_{i=1}^{n} Y_{c i}
$$

$$
N_{c}=\sum_{i=1}^{n} Y_{c i} L_{p c i}
$$

Where =lever of the force on $i$-th section

\subsection{Interaction Between Ships}

Interaction between ships is a confusing phenomenon and is very hard to simulate. The pressure field model helps improve the situation.

When ship moves ahead in water a pressure field is created (Fig. 8). Its actual form depends on the ship form and it extends for a considerable area around the ship. The pressure field exists no matter whether there is other ship in vicinity or not. Any disturbance created in this field necessarily has its reaction on the forces acting on the ship. If the disturbance takes place to one side of the ship, it is to be expected that the ship will, in general, be subject to a lateral force and a yawing moment.

Ship interaction happens when another ship passes in vicinity and disturbs the pressure field. Fig. 9 shows a sample result of an overtaking situation (Rawson [5]). It is for a ship A of $226 \mathrm{~m}$ and 36,890 tons overtaking a ship B of $173 \mathrm{~m}$ and 23,570 tons on a parallel course. Considering the interaction forces, ships are initially repelled, the force of repulsion reducing to zero when the bow of $\mathrm{A}$ is abreast the amidships of $B$. The ships are then attracted. The force becomes a maximum soon after the ships are abreast and then reducing and becomes a repulsion again as the ships

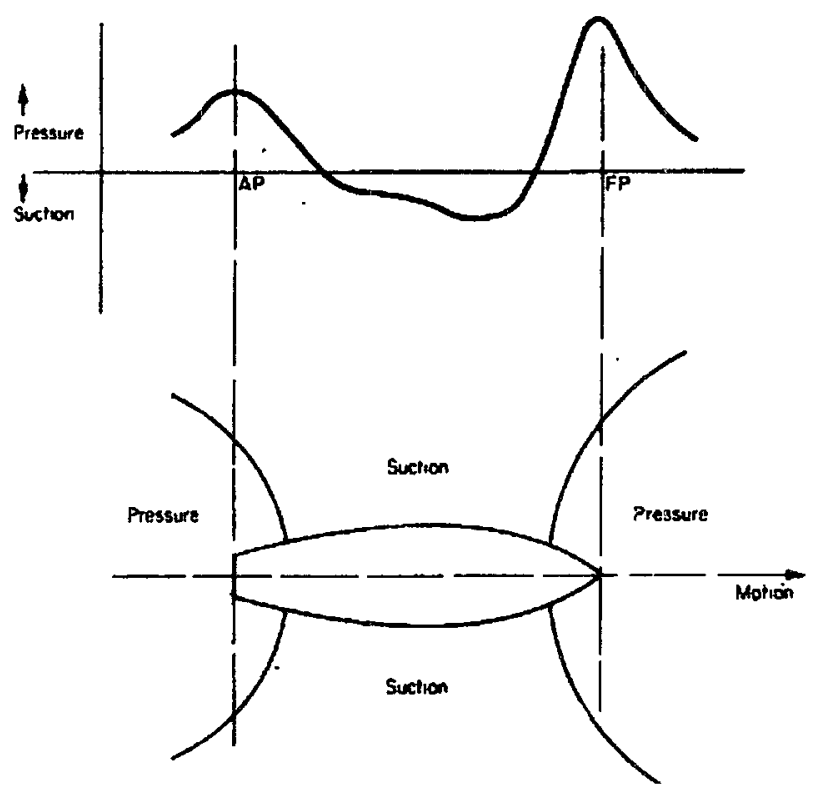

Fig. 8 Ship Pressure Field 


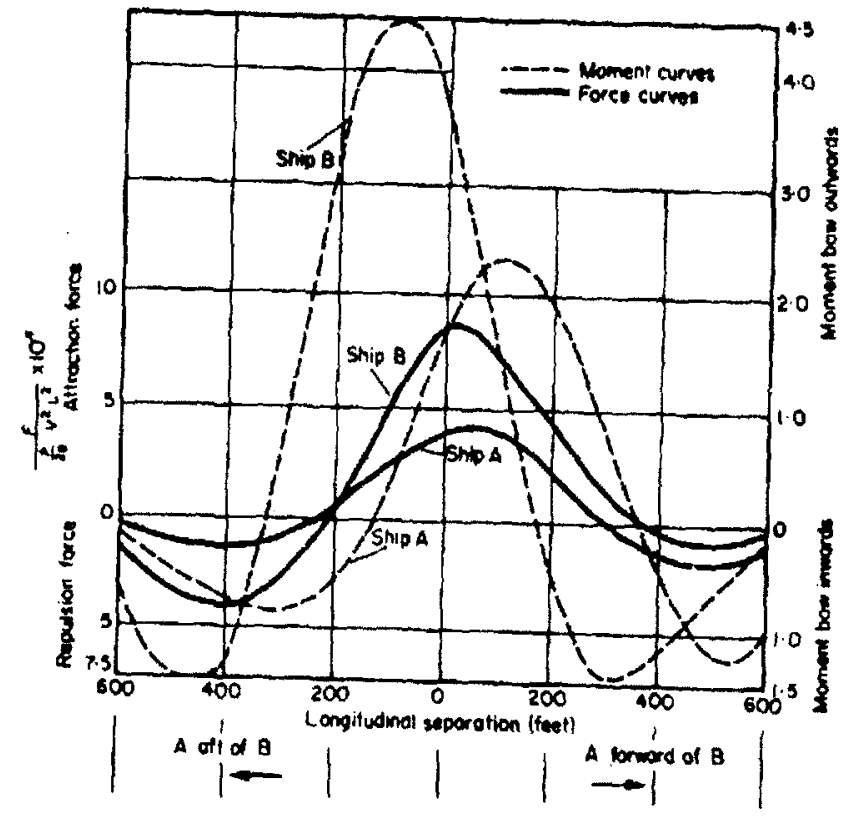

Fig. 9 Interaction Forces and Moments

begin to part company. The largest forces experienced were those of attraction when the two ships were abreast. The forces vary approximately as the square of the ship speed and inversely with the separation. As for the yawing moments, both ships are subject to a bow outward moment when running abreast and to a bow inward moment when approaching or breaking away.

To calculate interaction between ships, the following process can be performed, Define ship's pressure field according to hull form and ship speed, using grid method, Merge the pressure with that of another ship in vicinity, Divide longitudinal underwater portion of the ship into several sections and calculate forces caused by the merged pressure field, Sum up the overall effects using equations similar to Equation (10) and (11).

\subsection{Bank Effect Simulation}

When considering the bank effect, the question should be addressed is within what distance the bank effect should be take into account. Similar to the pressure field concept, a ship moving through the water will affect the water out to a certain distance on either side of the ship's sailing line. Beyond this distance the effects are exhausted by friction and gravity. This effective distance can be determined by:

$$
D=\frac{1}{2 b} \sqrt{101-\frac{L^{2}}{b^{2}}}
$$

where $D=$ Effective distance

$$
\begin{aligned}
& L=\text { Ship length between perpendiculars } \\
& b=\text { Beam of the vessel }
\end{aligned}
$$

This expression will predict the distance at which the effects of the vessel will be less than one percent. In many cases, the distance from the sailing line to the channel bank is less than the effective distance $D$ and so bank effect should be take into account.

In many cases bank effects are described based on ship's location (distance) from channel centerline. This works well for symmetrical channels and is also very useful in basic navigation channel study. However, it does not reflect real-world conditions very well. Real navigation channels are seldom completely symmetrical. When a channel is asymmetric, the distance used in determining bank suction effects must be measured from the neutral steering line (NSL) and not from the geometric centerline of the channel cross-section. The NSL is a line on which all lateral forces due to bank suction and cushion are counterbalanced and the yawing moment is zero.

To locate the NSL, the first consideration is to determine the effective width of the channel. This can be accomplished by applying Equation (12). Using the cross-section of the navigation channel, modified by the effective distance computation, the NSL can be determined by finding that line on each side of which the hydraulic radius for that side of the section is equal to the other side and also equal to the hydraulic radius of the entire section. The hydraulic radius can be calculated by:

$$
R=A / P
$$

where $R=$ Hydraulic radius

$A=$ Area of that part of the section

$P=$ Wetted perimeter of that part of the section

\section{Conclusions}

Besides the application in harbor and waterway design, simulators have been used for training of seafarers (Shiphandling. Radar Observation, Anti-Collision and Watchkeeping, Bridge Resource Management, etc.), marine casualty investigation, bridge design, etc. Each of the application may demand some specific functional capability in order to perform the task effectively and properly. For harbor and waterway design simulation, the special requirements 
should be considered at installation phase. Special attention should be paid to the simulator configuration and modeling of ship hydrodynamics. Fidelity and validity are important and large-scale simulation is necessary to ensure proper outcome. Channel navigation is a process of complicated operation in complicated environment and in most cases experienced mariners should be involved.

\section{REFERENCES}

[1] Bay, Jens. Integrating Bridge and Engine Simulator Systems. Proceedings of the eleventh International navigation Simulator Lecturers' Conference, Kalmar Maritime Academy, Sweden. August 2000. pp.6-11.

[2] Donaldson, Robert J. Unique Bridge Resource Management Program Optimizes Transfer of Training. Proceedings of the eleventh International navigation Simulator Lecturers' Conference, Kalmar Maritime
Academy, Sweden. August 2000. pp.6-11.

[3] International Maritime Organization, Interim Guidance on Training and Assessment in the Operational Use of the Electronic Chart Display and Information System (ECDIS) Simulators, STCW.7/Circ.10, June 2001.

[4] International Maritime Organization, Interim Standard for Ship Manoeuvrability, Resolution A751(18), November 1993.

[5] Rawson, K.J. and Tupper, E. C., Basic Ship Theory, 2nd Ed. Longman, London and New York, 1976. pp.509-511.

[6] Shi, C. and Cai, C., Development of SMU-IV Composite Shiphandling Simulator. Journal of Shanghai Maritime University. No. 4, Vol. 19, December 1998.

원고접수일 : 2001 년 10 월 15일

원고채택일 : 2002년 03월 18일 